\title{
COMPARATIVE STUDY OF MYCOFLORA, ANTIBACTERIAL ACTIVITY AND PHYTOCHEMISTRY OF SELECTED FRESH AND STORED MEDICINAL FRUITS
}

\author{
SUSHMA K. S., PUTTASWAMY RAJESHWARI, KOTESHWAR ANANDRAO RAVEESHA* \\ Centre for Innovative Studies in Herbal Drug Technology, Department of Studies in Botany, University of Mysore, Mysuru 570006 India \\ Email: karaveesha@gmail.com
}

Received: 31 May 2017 Revised and Accepted: 31 Aug 2017

\section{ABSTRACT}

Objective: To understand the mycoflora, phytochemical constituents and antibacterial potential of fresh and stored herbal fruits of selected plants, extensively used in herbal medicines.

Methods: Mycoflora analysis of Terminalia bellerica, Phyllanthus emblica and Myristica fragrans fruits was done employing serial dilution method, colony forming unit (CFU) and relative density of each fungi was recorded. The diversity of fungi associated with test fruits was calculated using various diversity indices. Methanol extracts of test fruits was subjected to preliminary phytochemical analysis, presence or absence of alkaloids, flavonoids, tannins, saponins, terpenoids, quinones and cardiac glycosides was detected. Antibacterial potential of test fruits was studied by well diffusion method.

Results: Fresh fruits were free of fungal contamination, whereas stored fruits were found in association with various fungi. A total of 64 isolates of 29 species belonging to 13 genera were identified from stored fruits. Aspergillus was predominant followed by Penicillium. T. bellerica was highly contaminated $\left(1 \times 10^{5} \mathrm{CFU} / \mathrm{g}\right)$. Stored fruits of $M$. fragrans recorded high fungal diversity with highest Simpson's diversity index (D-1=0.840) and Shannon-Wiener index ( $\mathrm{H}=2.888)$. P. emblica exhibited high species richness with high Margalef Richness (R=2.925), Menhinick index (E=1.830) and Berger Parker Dominance $\left(d^{\prime}=0.418\right)$. Phytochemical analysis of fresh and stored fruits did not show a significant difference in the presence or absence of tested phyto-constituents. Stored fruit extract recorded up to $41 \%$ increase in antibacterial activity.

Conclusion: Results suggests the need of proper training to the herbal material handler's right from the harvest to retail selling, and also points out the need to assess the fungal contamination of herbal materials before using them for herbal drug manufacture.

Keywords: Medicinal fruits, Storage condition, Mycoflora, Aspergillus niger, Bioactivity

(c) 2017 The Authors. Published by Innovare Academic Sciences Pvt Ltd. This is an open-access article under the CC BY license (http://creativecommons.org/licenses/by/4.0/) DOI: http://dx.doi.org/10.22159/ijpps.2017v9i10.20399

\section{INTRODUCTION}

Plants have been used in the prevention, treatment and cure of disorders and diseases since ancient times [1]. Medicinal plants are widely used as raw material for pharmaceutical preparations and as a supplement for dietetic products, specifically for self-medication [2]. In recent decades, the use of herbal preparations has increased in developing and developed countries, due to the belief that being natural, they are harmless [3]. With the ever-increasing use of herbal medicines worldwide and the rapid expansion of the global market for these herbal materials and preparations, the safety and quality of raw materials have become a major concern for health authorities, pharmaceutical industries and the public [4]. The quality of raw material used has a direct bearing on the safety and efficacy of the herbal drug.

Unfortunately, reports of people experiencing negative effects, caused by the use of herbal drugs, has been increasing. One of the reasons for such problem could be the poor quality of herbal drug raw material and insufficient attention being paid to the quality assurance and control of these herbal medicines. Although world health organisation (WHO) has developed guidelines for the quality control of herbal drugs which provide a detailed description of the techniques and measures required for the appropriate cultivation and collection of medicinal plants, there is still a lacuna between the available knowledge and implementation, because farmers and other relevant persons like producers, handlers and processors of herbal drugs are not much aware of WHO's guidelines. As a result, the quality control measures are ignored by the practitioners, resulting in an inferior quality of herbal drugs with lots of contaminants like heavy metals, pesticides and microbes [5].

Many of the herbal drugs are plant products, and they can be infested by bacteria and fungi, especially moulds. Unscientific method of cultivation and collection, inappropriate harvesting and cleaning, unsuitable transportation, inadequate drying and storage, poor hygiene of producer and congenial climatic conditions render the raw plant materials prone to microbial contamination in general and fungal infestation in particular [6]. Fungi are the predominant contaminants that survive during drying and storage. Mould contamination has been reported to alter the phytoconstituent of herbal drug raw materials [7] which in turn alters the therapeutic value of the herbs.

Considering these, three fruits widely used in herbal medicine viz. Terminalia bellerica (Gaertn.) Roxb. Phyllanthus emblica Linn. and Myristica fragrans Houtt. were selected for the study to understand the changes if any in the mycoflora, phytochemistry and antibacterial activity of fresh and stored fruits.

\section{MATERIALS AND METHODS}

\section{Collection of samples}

Dried and stored fruit samples of Terminalia bellerica (Gaertn.) Roxb. Phyllanthus emblica Linn. and Myristica fragrans Houtt. were randomly collected from different retail shops of the Mysuru city (Geographical coordinates in decimal degrees: Latitude $12.2979100^{\circ}$ and Longitude: $76.6392500^{\circ}$ ). Fresh fruits of $P$. emblica, T. bellerica and $M$. fragrans were collected from Biligiri Ranga hills (Geographical coordinates in decimal degree: Latitude $11.9^{\circ}$ and Longitude: $77.233333^{\circ}$ ) and Chandravana herbal farm of Mysuru (Geographical coordinates in decimal degree: Latitude $12.2979100^{\circ}$ and Longitude: $76.6392500^{\circ}$ ). The samples were collected in sterilized lock covers to avoid further contamination and stored in airtight containers at $4{ }^{\circ} \mathrm{C}$ until further analysis. All the specimens were deposited at Centre for Innovative Studies in Herbal Drug technology, DOS in Botany, University of Mysore, Mysuru and voucher number was obtained as MGB-CISHDT-RR-TB-SF-M-0008a, MGB-CISHDT-RR-PE-SF-M-0006a and MGB-CISHDT-RR-MF-SF-M0005 a for stored fruits of $T$. bellerica, $P$. emblica and $M$. fragrans 
respectively, and MGB-CISHDT-RR-TB-FF-M-0008b, MGB-CISHDTRR-PE-FF-M-0006b and MGB-CISHDT-RR-MF-FF-M-0005b for fresh fruits of T. bellerica, P. emblica and M. fragrans respectively.

\section{Chemicals and reagents}

Chemicals/Reagents: Source

Nutrient Agar, Nutrient Broth and Czapek Dox Agar: HiMedia Laboratories Pvt. Ltd., Mumbai.

Mercuric chloride: Chemicals division, Glaxo Laboratories (India) Ltd., Mumbai

Ferric chloride, Potassium iodide and Sodium iodide: Fisher Scientific, Thermos electron LLS India Pvt. Ltd, Navi Mumbai

Hcl: Qualigens fine chemicals glaxosmithkline pharmaceutical limited, Mumbai

Bismuth carbonate, Lead acetate, Zinc, $\mathrm{H}_{2} \mathrm{SO}_{4}$ and Acetic anhydride: Fisher Scientific India Pvt. Ltd. Sion (East) Mumbai

Sodium bicarbonate, Glacial acetic acid: Sisco Research Laboratory Pvt. Ltd. Bombay

Methanol, Chloroform and Ethyl acetate: SDFCL sd fine chemicals limited, Mumbai

\section{Mycoflora analysis}

Serial dilution method [8] was employed to determine the colony forming unit (CFU) of fungi. One gram of each sample transferred into $20 \mathrm{ml}$ screw capped bottles containing $9 \mathrm{ml}$ of sterile distilled water and was mechanically homogenized at a constant speed for 15 min on an electronic shaker. The sample-water suspension was allowed to stand for $10 \mathrm{~min}$ with intermittent shaking before being plated. Appropriate ten-fold serial dilutions (1:10) were prepared and $1 \mathrm{ml}$ aliquot of each dilution was aseptically surface plated and distributed uniformly on culture medium with the help of sterilized L-shaped glass spreader. Freshly prepared czapek dox agar (CDA) medium served as the culture medium. Plates were incubated at $28 \pm 2{ }^{\circ} \mathrm{C}$ for $7 \mathrm{~d}$ and observed daily. Subsequently, the CFU, diversity and density of the fungi were recorded. Morphologically different mould colonies were individually sub-cultured by hypha tip method on CDA medium and their pure cultures were maintained.

Colony forming units of fungi per gram of fruit ( $\mathrm{CFU} / \mathrm{g}$ ) was calculated using the formula

$\mathrm{CFU}=\mathrm{N} \times 10^{-\mathrm{n}}$ where $\mathrm{N}=$ total no of colonies, $\mathrm{n}=$ dilution [9]

All the isolated fungal species were identified on the basis of their cultural and morphological characteristics with the help of standard manuals.

The relative density of each fungi was calculated using the formula:

Relative density of fungi

$$
\begin{aligned}
& =\frac{\text { No. of colony of individual fungus }}{\text { Total no. of colonies of all fungal species }} \\
& \times 100
\end{aligned}
$$

\section{Calculation of diversity indices}

Shannon Weiner index (H) $\left[\mathrm{H}^{\prime}=-3.3219 \sum n_{i} / N \log n_{i} / N\right]$, Margalef's richness index (R) $[\mathrm{d}=\mathrm{S}-1 / \log \mathrm{N}]$ and Menhinick index $[\mathrm{Dmm}=\mathrm{S} / \sqrt{\mathrm{N}}]$ was calculated to determine the Species richness of fungi in the herbal fruits. Evenness of fungal distribution was calculated through Berger Parkers dominance index $\left(d^{\prime}\right)\left[d^{\prime}=n_{\max } / N\right]$. The diversity of fungi was determined by Simpson's diversity index (1-D) [1-D $\left.=1-\sum n_{i}-\left(n_{i}-1\right) / N-(N-1)\right]$. Online webpage calculator (http://www.alyoung.com/labs/biodiversity_calculator.html) was used for the calculation of diversity indices.

\section{Extract preparation}

The fresh and stored fruits of P. emblica, T. bellerica, and M. fragrans were powdered with the help of a waring blender. $100 \mathrm{~g}$ of each of the powder was extracted with methanol by cold extraction method. The extract was concentrated by evaporation and preserved at $4{ }^{\circ} \mathrm{C}$ until subjected to antibacterial activity assay [10] and phytochemical analysis.

\section{Preliminary phytochemical analysis}

The methanol extracts of the fruits were subjected to the detection of alkaloids, flavonoids, tannins, saponins, terpenoids, quinones and cardiac glycosides following the methods of Trease et al., and Sofowara [11, 12].

\section{Test bacteria}

Authentic pure cultures of phytopathogenic bacteria Xanthomonas campestris pv. vesicatoria (MTCC 2286) and Xanthomonas campestris pv. campestris (NCIM 5028) were obtained from Microbial Type Culture Collection, IMTECH, Chandigarh and National Centre of Industrial Microorganism, NCL, Pune respectively. Xanthomonas oryzae pv. oryzae, isolated from the diseased plant was obtained from the culture collections of Centre for Innovative Studies in Herbal Drug Technology, Department of Studies in Botany, University of Mysore, Mysuru. All the test bacteria were sub-cultural on nutrient agar. Twoday old nutrient broth cultures of the test bacteria were used for assay.

\section{Antibacterial activity assay}

Antibacterial activity of methanol extract was determined by well diffusion method on nutrient agar medium. Wells $(6 \mathrm{~mm})$ were made in nutrient agar plates using sterile cork borer and $50 \mu 1$ of inoculums of test bacteria was spread on the solid plates with a sterile swab. Then $100 \mu 1$ of the extract was poured into the wells. The treatment also included $100 \mu 1$ of methanol separately which served as control. The plates were incubated for $24 \mathrm{~h}$ at $37^{\circ} \mathrm{C}$ and zone of inhibition if any around the wells were measured in $\mathrm{mm}$ and recorded [13].

\section{RESULTS}

\section{Mycoflora analysis}

Following serial dilution method, a total of 64 isolates of fungi were recorded from the stored herbal fruits while fresh fruit samples were free from fungal contamination. A maximum number of 24 isolates belonging to 12 species viz., Aspergillus niger, A. tamarii, Penecillium citrinum, Penicillium oxalicum, P. commune, Penicillium sp., Cladosporium sp., Heterociphalum, Chaetomium sp., Pestalotiopsis sp., Mycoleptodiscus sp. and one sterile fungi were recorded from Phyllanthus emblica (table 1). Eighteen isolates belonging to 10 species viz., Aspergillus niger, Aspergillus flavus, A. minutus, A. candidus, A. terricola, Curvularia trifolii, C. lunata, Penicillium pinophilum, Alternaria helanthi and one sterile fungus were isolated from Terminalia bellerica (table 2). Stored fruits of $M$. fragrans recorded 22 isolates belonging to 11 species viz., Aspergillus niger, Aspergillus flavus, A. parasiticus, A. ochraceous, A. terreus, A. versicolor, Penicillium purpurogenum, P. commune, Heliminthosporium sorghicola and Rhisopus sp. (table 3).

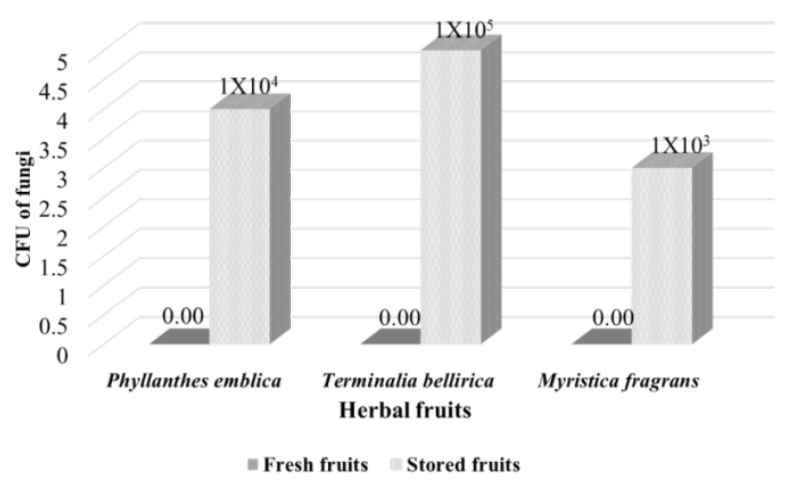

Fig. 1: Fungal contamination of fresh and stored herbal fruits

Stored fruits of $P$. emblica was found in association with 12 different fungal species belonging to 8 genera. The genus Penicillium was found to be predominant recording 4 species followed by Aspergillus 
with two species. Among 12 species, A. niger recorded the highest relative density (82.608) followed by $P$. commune with a density of $31.63 \%$ (table 1). In case of $T$. bellerica 10 species of 5 different genera were observed among these the genus Aspergillus was found to be predominant comprising 5 species, this was followed by Curvularia (2 species). A. niger and A. flavus recorded highest relative density of 61.90 and 52.38 respectively in the stored fruits of $T$. bellerica (table 2). Eleven different species belonging to 4 genera were isolated from stored fruits of $M$. fragrans, with 7 species
Aspergillus being the predominant one, followed by Penicillium (2 species). A. versicolor was found to be predominant in stored fruits of M. fragrans with the highest relative density of 60 (table 3). Fig. 1 presents the $\mathrm{CFU}$ of fungi per gram of test fruits.

Highest CFU of $1 \mathrm{X} 10^{5}$ was recorded in T. bellerica followed by $1 \mathrm{X} 10^{4}$ in $P$. emblica and $1 \times 10^{3}$ in M. fragrans. CFU of each fungal isolate is presented in the tables 1-3. A. niger was found to be most predominant fungi in all the test fruits.

Table 1: Diversity, CFU and density of fungal contaminants isolated from fresh and stored fruits of Phyllanthus emblica

\begin{tabular}{|c|c|c|c|c|c|}
\hline \multirow[t]{2}{*}{ S. No. } & \multirow[t]{2}{*}{ Fungal contaminants } & \multicolumn{2}{|c|}{ Stored fruits } & \multicolumn{2}{|c|}{ Fresh fruits } \\
\hline & & $\mathrm{CFU} / \mathrm{ml}$ & Density (\%) & $\mathrm{CFU} / \mathrm{ml}$ & Density (\%) \\
\hline 1 & Aspergillus niger & $6 \times 10^{2}$ & 82.608 & 00 & 00 \\
\hline 2 & A. tamarii & $7 \times 10^{2}$ & 4.545 & 00 & 00 \\
\hline 3 & Penicillium citrinum & $3 \times 10^{2}$ & 13.636 & 00 & 00 \\
\hline 4 & P. oxalicum & $4 \times 10^{4}$ & 18.181 & 00 & 00 \\
\hline 5 & P. commune & $7 \times 10^{2}$ & 31.818 & 00 & 00 \\
\hline 6 & Cladosporium sp. & $1 \times 10^{2}$ & 4.545 & 00 & 00 \\
\hline 7 & Heterociphalum & $1 \times 10^{2}$ & 4.545 & 00 & 00 \\
\hline 8 & Mycoleptodiscus sp. & $1 \times 10^{2}$ & 4.545 & 00 & 00 \\
\hline 9 & Pestalotiopsis sp. & $1 \times 10^{1}$ & 7.142 & 00 & 00 \\
\hline 10 & Penicillium sp. & $2 \times 10^{2}$ & 14.286 & 00 & 00 \\
\hline 11 & Chaetomium sp. & $2 \times 10^{2}$ & 14.286 & 00 & 00 \\
\hline 12 & Sterile fungi-1 & $1 \times 10^{1}$ & 14.286 & 00 & 00 \\
\hline
\end{tabular}

Table 2: Diversity, CFU and density of fungal contaminants isolated from fresh and stored fruits Terminalia bellerica

\begin{tabular}{|c|c|c|c|c|c|}
\hline S. No. & Fungal contaminants & $\begin{array}{l}\text { Stored fruits } \\
\text { CFU/ml }\end{array}$ & Density (\%) & $\begin{array}{l}\text { Fresh fruits } \\
\text { CFU/ml }\end{array}$ & Density (\%) \\
\hline 1 & Aspergillus niger & $6 \times 10^{1}$ & 61.90 & 00 & 00 \\
\hline 2 & A. flavus & $5 \times 10^{2}$ & 52.38 & 00 & 00 \\
\hline 3 & A. minutus & $1 \times 10^{4}$ & 4.76 & 00 & 00 \\
\hline 4 & A. candidus & $2 \times 10^{2}$ & 9.52 & 00 & 00 \\
\hline 5 & A. terricola & $2 \times 10^{2}$ & 9.52 & 00 & 00 \\
\hline 6 & Curvularia trifolii & $3 \times 10^{3}$ & 14.28 & 00 & 00 \\
\hline 7 & Curvularia lunata & $2 \times 10^{2}$ & 7.142 & 00 & 00 \\
\hline 8 & Penicillium pinophilum & $3 \times 10^{3}$ & 7.142 & 00 & 00 \\
\hline 9 & Alternaria helanthi & $6 \times 10^{1}$ & 21.42 & 00 & 00 \\
\hline 10 & Sterile fungi-2 & $2 \times 10^{2}$ & 7.142 & 00 & 00 \\
\hline
\end{tabular}

Table 3: Diversity, CFU and density of fungal contaminants isolated from Myristica fragrans

\begin{tabular}{lllll}
\hline S. No. & Fungal contaminants & Stored fruits & & Fresh fruits \\
\cline { 3 - 5 } & & CFU/ml & Density (\%) & CFU/ml \\
\hline 1 & Aspergillus niger & $13 \times 10^{1}$ & 43.75 & 00 \\
2 & A. flavus & $12 \times 10^{2}$ & 51.42 & 00 \\
3 & A. ochraceous & $4 \times 10^{1}$ & 5.714 & 00 \\
4 & A. parasiticus & $2 \times 10^{2}$ & 34.7 & 00 \\
5 & A. terreus & $5 \times 10^{1}$ & 11.42 & 00 \\
6 & A. versicolor & $20 \times 10^{1}$ & 60.00 & 00 \\
7 & Aspergillus sp. & $8 \times 10^{1}$ & 37.5 & 00 \\
8 & Penicillium commune & $2 \times 10^{1}$ & 6.25 & 00 \\
9 & P. purpurogenum & $2 \times 10^{2}$ & 6.25 & 00 \\
10 & Rhisopus sp. & $6 \times 10^{2}$ & 8.571 & 00 \\
11 & Heliminthosporium sorghicola & $6 \times 10^{3}$ & 00 & 00 \\
\end{tabular}

Table 4: Diversity indices of fungi associated with stored herbal fruits

\begin{tabular}{lll}
\hline Diversity indices & P. emblica & T. bellirica \\
\hline Species richness & 12 & 10 \\
Simpson's diversity index index (1-D) & 0.794 & 11 \\
Shannon-Wiener index (H) & 2.788 & 0.799 \\
Margalef Richness index (R) & 2.925 & 2.625 \\
Menhinick index of evenness (E) & 1.83 & 2.474 \\
Berger Parker Dominance index (d') & 0.418 & 2.884 \\
\hline
\end{tabular}

\section{Diversity indices}

The diversity indices of fungi associated with stored herbal fruits is presented in table 4. Highest diversity of fungi was observed in fruits of $M$. fragrans with Simpson's diversity index of D-1=0.840 and Shannon-Wiener index of $\mathrm{H}=2.888$ followed by P. emblica (D-
1=0.799; $\mathrm{H}=2.788$ ) and T. bellirica (D-1=0.794; $\mathrm{H}=2.625$ ). High species richness (12) of fungi was recorded in P. emblica fruits showing high Margalef Richness index $(\mathrm{R}=2.925)$, Menhinick index of evenness $(\mathrm{E}=1.830)$ and Berger Parker Dominance index $\left(d^{\prime}=0.418\right)$ values followed by $T$. bellerica $(\mathrm{R}=2.474 ; \mathrm{E}=1.622$; $\left.\mathrm{d}^{\prime}=0.352\right)$ and $M$. fragrans $\left(\mathrm{R}=2.295 ; \mathrm{E}=1.246 ; \mathrm{d}^{\prime}=0.269\right)$. 


\section{Preliminary phytochemical analysis}

The methanol extract of both stored and fresh fruits of $P$. emblica showed the presence of alkaloids, flavonoids, tannins, saponins, steroids, phenols and quinones. Fresh and stored sample of $T$. bellerica was found to possess flavonoids, tannins, steroids, terpenoids, phenols and quinones. Flavonoids, steroids and terpenoids were detected in M. fragrans extract (table 5).

Table 5: Phytochemical analysis of solvent extracts of herbal fruits

\begin{tabular}{|c|c|c|c|c|c|c|}
\hline Phytochemical tests & $\begin{array}{l}\text { ME of stored } \\
\text { T. bellerica } \\
\end{array}$ & $\begin{array}{l}\text { ME of fresh } \\
\text { T. bellerica }\end{array}$ & $\begin{array}{l}\text { ME of stored } \\
\text { P. emblica }\end{array}$ & $\begin{array}{l}\text { ME of fresh } \\
\text { P. emblica }\end{array}$ & $\begin{array}{l}\text { ME of stored } \\
\text { M. fragrans }\end{array}$ & $\begin{array}{l}\text { ME of fresh } \\
\text { M. fragrans }\end{array}$ \\
\hline Alkaloids & - & - & + & + & - & - \\
\hline Flavonoids & + & + & + & + & + & + \\
\hline Tannins & + & + & + & + & - & - \\
\hline Saponins & - & - & + & + & - & - \\
\hline Steroids & + & + & + & + & + & + \\
\hline Terpenoids & + & + & + & + & + & + \\
\hline Phenols & + & + & + & + & - & - \\
\hline Quinones & + & + & + & + & - & - \\
\hline Cardiac glycosides & + & + & + & + & + & + \\
\hline
\end{tabular}

+indicate the presence and-indicate the absence

\section{Antibacterial activity assay}

Methanol extracts of all test fruits recorded variable activity against all the tested bacteria with a zone of inhibition ranging between 18 $\mathrm{mm}$ to $30 \mathrm{~mm}$ (table 6). Stored fruits exhibited comparatively higher antibacterial activity than the fresh fruits. An increase of $7 \mathrm{~mm}$ zone of inhibition was observed against Xanthomonas campestris pv. vesicatoria in the contaminated fruits of $M$. fragrans and an increase of $6 \mathrm{~mm}$ was observed against Xanthomonas oryzae pv. oryzae in the contaminated $T$. bellerica fruit. Similarly, an increase of $3 \mathrm{~mm}$ inhibition was recorded in stored fruits of $P$. emblica against Xanthomonas campestris pv. vesicatoria (table 6).

Table 6: Antibacterial activity of methanol extracts of Terminalia bellerica, P. emblica and M. fragrans against test bacteria (Zone of inhibition in mm)

\begin{tabular}{|c|c|c|c|c|c|c|}
\hline \multirow{2}{*}{$\begin{array}{l}\text { Test } \\
\text { bacteria }\end{array}$} & \multicolumn{6}{|c|}{ Zone of inhibition in $\mathbf{m m}$} \\
\hline & $\begin{array}{l}\text { ME of stored fruits } \\
\text { of } T \text {. bellerica }\end{array}$ & $\begin{array}{l}\text { ME of fresh fruits } \\
\text { of T. bellerica }\end{array}$ & $\begin{array}{l}\text { ME of stored fruits } \\
\text { of } P \text {. emblica }\end{array}$ & $\begin{array}{l}\text { ME of fresh fruits } \\
\text { of } P \text {. emblica }\end{array}$ & $\begin{array}{l}\text { ME of stored fruits } \\
\text { of } M \text {. fragrans }\end{array}$ & $\begin{array}{l}\text { ME of fresh fruits } \\
\text { of M. fragrans }\end{array}$ \\
\hline X.c. pv. c. & $27.02 \pm 0.01$ & $27.00 \pm 0.00$ & $28.01 \pm 0.01$ & $25.02 \pm 0.01$ & $24.00 \pm 0.00$ & $17.00 \pm 0.00$ \\
\hline$X . c$. pv. v. & $30.01 \pm 0.01$ & $30.02 \pm 0.01$ & $27.03 \pm 0.01$ & $26.05 \pm 0.00$ & $26.05 \pm 0.00$ & $24.01 \pm 0.01$ \\
\hline X. o. pv. o. & $27.01 \pm 0.01$ & $21.01 \pm 0.01$ & $28.01 \pm 0.00$ & $28.01 \pm 0.00$ & $19.01 \pm 0.00$ & $18.01 \pm 0.00$ \\
\hline
\end{tabular}

Values are the mean of three replicates \pm standard Error, $\mathrm{P}$ value $=0.00 \leq 0.05$, Note: ME-Methanol extract; X. . pv. . - Xanthomonas campestris pv. vesicatoria, X. c. pv. c.-Xanthomonas campestris pv. campestris and X. o. pv. o.-Xanthomonas oryzae pv. Oryzae

\section{DISCUSSION}

The traditional system of herbal medicine has become a topic of global importance both as medicinal and economical [14] since they are considered as rich sources of lead compounds and quietly safe for both human use and environment-friendly [15]. Considering this in the present study, assessment of fungal contamination of selected fresh and stored herbal fruits was done by employing serial dilution method. Results revealed that the stored fruits were contaminated with various fungi whereas fresh fruits were found to be free of fungal contaminants.

The occurrence of the high diversity of fungi of 64 isolates of 29 species belonging to 13 genera indicates the association of broad spectrum of mycobiota in stored fruits. Among these P. emblica was found to be highly contaminated with 12 species of fungi belonging to 8 genera followed by $M$. fragrans with 11 species, belonging to 4 genera and $T$. bellerica with 10 species, belonging to 5 genera.

Fungal contamination of $M$. fragrans $[14,16]$ P. emblica $[18,19]$ and T. bellerica [20] has been reported. Results of the previous study correlates with the results obtained in the present investigation, but the diversity and density of fungal contaminants recovered varies. Akhund et al., [19] have recorded Aspergillus, Penicillium, Fusarium, Alternaria, Cladosporium and Curvularia from P. emblica stored fruits and reported that $A$. niger and A. flavus are the predominant fungi. Gautam and Bhadauria [18] have isolated Aspergillus, Penicillium Helminthosporium, Rhizopus, Syncephalastrum, Alternaria, and Curvularaia from P. emblica and T. bellerica. Rajeshwari and Raveesha [21] have reported fungal contamination of $A$. calamus roots, $M$. fragrans mace, $C$. angustifolia and $C$. asiatica leaves, $T$. cordifolia and W. somnifera stem collected from the retail herbal shops of Mysuru. Mycoflora analysis of the herbal fruits is done in various parts of the world including India, but no reports are available on fungal contamination of M. fragrans, P. emblica and T. bellerica fruits of Mysuru, which is an important hub of the herbal drug raw materials markets. Thus the present work is the first to report on the mycoflora of the stored herbal drug fruits from this region.

Diversity indices calculation revealed the occurrence of highest fungal diversity on $M$. fragrans recording high Simpson's diversity index (D-1=0.840) and Shannon-Wiener index $(\mathrm{H}=2.888)$. Although $M$. fragrans did not possess a high number of fungal species, the highest diversity was recorded in $M$. fragrans, as the term diversity considers not only the species richness but also the even distribution of species. On the other hand, P. emblica recorded high species richness (12), high dominance and evenness $(\mathrm{R}=2.925$; $\mathrm{E}=1.83 ; d^{\prime}=0.418$ ) but not the diversity. This pattern of results may be due to the fact that, A. niger being fast growing and dominant may inhibit the growth of other fungal species. This is justified by the results observed in this investigation, wherein $A$. niger was recorded with high density (82.608) on P. emblica than on the T. bellerica (61.90) and M. fragrans (43.75). Sharma et al. [22] have studied species richness (S), Shannon-Wiener's diversity index ( $\left.\mathrm{H}^{\prime}\right)$, Simpson Dominance index $(\mathrm{Cd})$ and Berger Parker's Dominance index (d') diversity indices of fungi recorded from dried fruit samples of Phyllanthus emblica, Terminalia bellerica and Terminalia chebula from Jammu and Kashmir. Unlike the results of present study, they have recorded high species richness (55) and diversity (ShannonWiener's diversity index $=1.634$ ) and least Simpson dominance index $(0.028)$ and Berger-Parker's dominance index $(0.053)$ on P. emblica fruits. 
During the collection of stored fruits from the market, it was observed that the samples were displayed on open metal/plastic containers/wooden boxes/gunny bags or on the bare ground in local general stores, causing direct exposure to airborne bio-pollutants which may have resulted in fungal contamination. Apparently, healthy fresh fruit samples were collected directly from the plant and brought to the laboratory in sterilized lock covers and analyzed and did not show any fungal contamination.

The genus Aspergillus was found to be predominant genus recording 12 species. Apart from this 6 species of Penicillium, 2 species of Curvularia and one species each of Alternaria, Helminthosporium, Cladosporium, Heterociphalum, Chaetomium, Pestalotiopsis, Mycodypteria and 2 sterile fungi were recorded. Species of Aspergillus and Penicillium has been reported as the dominant mycoflora in some herbal drug raw materials collected from Tokyo (Japan); Hunan, Hubei and Guangxi province (China); Gwalior (North India) [23-25] the results of the present study also revealed the same. The association of A. niger in high density from all fruit samples, which are used by consumers, should be taken seriously as some strains can produce mycotoxins like ochratoxin A [26].

Fungal contaminants have been reported to affect the chemical compositions of the herbal drug raw materials on which they grow and thereby alter the medicinal property [7]. In order to understand the effect of fungal contamination on phytochemical constituents of both fresh (free of fungal contamination) and stored fruits (contaminated with fungi), methanol extracts of the same were screened for the phytochemical constituents. The extracts of test samples were tested for the presence of alkaloids, flavonoids, tannins, saponins, steroids, terpenoids, phenols, quinones and cardiac glycosides. Methanol was the preferred solvent for extraction since it is known to dissolve most of the secondary metabolites due to its polar nature.

Previous reports state the presence of alkaloids, tannins [27], flavonoids, saponins, phenols, anthraquinones, cardiac glycosides, coumarins, anthocyanin, chalcones, emodins, and triterpenoids [28] in M. fragrans. Dhale and Mogle [29] have found the presence of alkaloids, glyceroids, phenols, tannins, lignin, saponins, flavonoids and terpenoids in P. emblica. Devi et al. [30] and Abraham et al. [31] have detected alkaloids, flavonoids, tannins, glycosides, phenols and saponin in T. bellerica.

In the present investigation methanol extracts of fresh and stored fruits of $P$. emblica showed positive results for all the tested phytochemicals. Fresh and stored fruit samples of T. bellerica was found to possess flavanoid, tannins, steroid, terpenoids, phenols and cardiac glycosides. M. fragrans fresh and stored samples showed the presence of flavonoids, steroids, terpenoids and cardiac glycosides. Results did not show any significant difference in the presence or absence of test phytochemical constituents between fresh and stored herbal fruits. However, there could be adding some new compounds which have not been tested. Further quantitative and qualitative analysis need to be done to draw clear inferences on the role of fungal contamination on phytochemical constituents of tested fruits.

To understand the antibacterial potential of methanol extracts of selected fresh and stored herbal fruits, antibacterial activity assay was carried out against three plant pathogenic bacteria. Methanol extracts of all the tested samples showed antibacterial activity against all the test bacteria with varying zones of inhibition ranging between $24 \mathrm{~mm}$ and $30 \mathrm{~mm}$. The presence of more phytochemicals in an extract correlates with more potential activity exhibited by that extract as the $M$. fragrans extract which showed presence of 4 phytochemicals (flavonoids, steroids, terpenoids and cardio glycosides) out of 9 tested, exhibited least antibacterial activity zone between 17 and $26 \mathrm{~mm}$ whereas extracts of $P$. emblica and T. bellerica recording presence of all and 7 phytochemicals out of 9 tested exhibited zone of inhibition range between $25-28 \mathrm{~mm}$ and 21 $30 \mathrm{~mm}$ respectively. Antimicrobial activity of $P$. emblica [29, 32], $M$. fragrans $[27,33]$ and $T$. bellerica [34-36] is reported by researchers against some human pathogenic bacteria but not against plant pathogenic bacteria. Results of the present investigation demonstrate the antimicrobial potential of test fruits on phytopathogenic bacteria.
Although stored fruits were found in association various fungi they exhibited a comparatively larger zone of inhibition i.e. upto $41 \%$ more than the fresh fruit extracts which were free of contamination. Stored fruit of $M$. fragrans showed an increase of $41 \%$ inhibition against Xanthomonas campestris pv. campestris, $8.33 \%$ against Xanthomonas campestris pv. vesicatoria and $5.55 \%$ against Xanthomonas oryzae pv. oryzae. An increase of $28 \%$ of zone of inhibition was observed in stored fruits of $T$. bellerica against Xanthomonas oryzae pv. oryzae. An increase of $12 \%$ and $3.8 \%$ zone of inhibition was recorded in stored fruits of $P$. emblica against Xanthomonas campestris pv. campestris and Xanthomonas campestris pv. vesicatoria respectively. This may be due to the predisposition of stored fruits to stress conditions during drying and fungal infestation that might have resulted in the production of more or new secondary metabolites, responsible for the antibacterial property. However, this needs further investigation on quantification and characterization of active principle present in fresh and stored fruits for the better understanding.

\section{CONCLUSION}

Analysis of fresh fruit samples showed that fruits were free of fungal contaminants while the stored fruits were contaminated with fungi, but it was within the maximum permitted limit prescribed by WHO. However the occurrence of a high diversity of fungi that are capable of causing bio-deterioration and producing fungi mycotoxins viz., Aspergillus, Penicillium and Alternaria is a cause of concern. Results clearly indicate the need for adaptation of appropriate methods for harvesting, collection, transportation, handling and storage of herbal drug raw materials. Maintenance of hygienic condition may be helpful in the prevention of fungal contamination. Though there was no significant difference in the phytochemical constituents as well as the antibacterial potential of both fresh and stored samples. Long term storage may affect the quality of the herbal fruits, due to increased growth of mycobiota, which in turn may affect the phytochemical composition and antibacterial potential. Hence proper handling and storage methodology is a prerequisite for the maintenance of herbal drug raw materials. The results suggest proper training need to be provided herbal material handlers right from harvesting to retail selling.

\section{ACKNOWLEDGEMENT}

The authors are thankful to University Grants Commission-Rajiv Gandhi National Fellowship (UGC-RGNF), New Delhi and VGST, Govt. of Karnataka, for financial assistance.

\section{AUTHORS CONTRIBUTION}

\section{First (Sushma K. S.): Acquisition of data}

Second Author (Rajeshwari P.): Data interpretation and Drafting the manuscript

Third author (K. A. Raveesha): Conception and design of study

\section{CONFLICT OF INTERESTS}

No potential conflict of interest was reported by the authors

\section{REFERENCES}

1. Tyagi R, Sharma G, Jasuja ND, Menghani E. Indian medicinal plants as an effective antimicrobial agent. J Cancer Res 2016;3:61-79.

2. Moorthy K, Prasanna I, Thajuddin N, Arjunan S, Gnanendra TS, Hussain MIZ. Occurrence of mycopopulation in spices and herbal drugs. Int J Biol Technol 2010;1:6-14.

3. Kosalec I, Cvek J, Tomic S. Contamination of medicinal herbs and herbal products. AHRT 2005;60:485-501.

4. Anonymous. WHO guidelines for assessing quality of Herbal medicines with reference to contaminants and residues; 2007.

5. McGuffin M, Hobbs C, Upton R, Goldberg A. American herbal products association's botanical safety handbook; 1997. p. 7-8.

6. Stevic T, Pavlovic S, Stankovic S, Savikin K. Pathogenic microorganisms of medicinal herbal drugs. Arch Biol Sci 2012;64:49-58.

7. Singh P, Srivastava B, Kumar A, Dubey NK. Fungal contamination of raw material of some herbal drugs and recommendation of Cinnamomum camphoraoil as herbal fungi toxicant. Microb Ecol 2008;56:555-60. 
8. Koch R. Über die neuen untersuchungsmethoden zum nachweis der mikrokosmen in boden, luft und wasser. In: Faffky G, Pfuhl E, Schalbe J. Herausg Gesammelte Werke von Robert Koch. Verlag Georg Thieme, Leipzig; 1883;1:274-84.

9. Sharma S, Gupta M, Bhadauria R. Mycibiota of commercially available triphala powder: a well-known dietary supplement of Indian system of medicine. J Mycol 2014;1-8. http://dx.doi.org/10.1155/2014/836036.

10. Abah SE, Egwari LO. Methods of extraction and antimicrobial susceptibility testing of plant extracts. Afr J Basic Appl Sci 2011;3:205-9.

11. Trease GE, Evans WC. Pharmacognosy. 11th ed. Bailliere Tindall, London; 1989. p. 45-50.

12. Sofowara EA. Medicinal plants and traditional medicine in Africa. Spectrum Books Ltd., Ibadan, Nigeria; 1993. p. 191-289.

13. Varghese LS, Ninan MA, Alex N, Soman S, Jacob S. Comparative antibacterial activity of fruit extracts of Emblica officinalis gaerth against gram-positive versus gram-negative bacteria. Indian J Clin Biochem 2013;6:447-52.

14. Kamath KK, Shabaraya AR. Comparison of antibacterial activity of leaves extracts of Tectona grandis, Mangifera indica, and Anacardium occidentale. Int J Chem Pharm Res 2017;1;36-9.

15. Pradeepa M, Kalidas V, Geetha N. Qualitative and quantitative phytochemical analysis and bactericidal activity of Pelargonium graveolens L'Her. Int J Appl Pharm 2016;8:7-11.

16. Pesavento G, Ostuni M, Calonico C, Rossi S, Capei R, Nostro Al. Mycotic and aflatoxin contamination in Myristica fragrans seeds (nutmeg) and Capsicum annum (chilli), packaged in Italy and commercialized worldwide. I Preventive Med Hygiene 2016;57:102-9.

17. Dharmaputra OS, Ambarwati S. Fungal infection and aflatoxin contamination in stored nutmeg (Myristica fragrans) kernels at various stages of delivery chain in North Sulawesi province. Biotropia 2015;22:129-39.

18. Gautam AK, Bhadauria R. Mycoflora and mycotoxins in some imported stored crude and powdered herbal drugs. Biol Forum Int J 2009;1:1-7.

19. Akhund S, Suhail M, Rani I, Memon FI, Abro H. Fruit borne Mycoflora of amla (Phyllanthus emblica L.). Pak J Bot 2010;42:4229-33

20. Ajay K, Gautam. Fungal contamination of few common stored herbal fruit samples. Int J Nutr Wellness 2009;8:1-7.

21. Rajeshwari P, Raveesha KA. Mycological analysis and aflatoxin B1 contaminant estimation of herbal drug raw materials. Afr Tradit Complementary Altern Med 2015;13:123-31.

22. Sharma S, Sumbali G, Sharma V. Natural occurrence of diverse fungal species and their toxins in dried fruits of Emblica officinalis, Terminalia chebula and T. bellerica-constituents of triphala, an important ayurvedic preparation of India. IOSR J Pharm Biol Sci 2016;11:6-13.
23. Hitokoto H, Morozumi $\mathrm{S}$, Wauke $\mathrm{T}$, Kurata H. Fungal contamination and mycotoxin detection of powdered herbal drugs. Appl Environ Microbiol 1978;36:252-6

24. Aziz NH, Youssef YA, Ei-fouly MZ, Moussa LA. Contamination of some common medicinal plant sample and spices by fungi and their mycotoxins. Bot Bull Acad Sin 1998;39:279-85.

25. Gautham AK, Bhadauria R. Mycoflora and mycotoxins in some important stored crude and powdered herbal drugs. Biol Forum Int J 2009;1:1-7.

26. Gautham AK, Avasthi S, Sharma A, Bhadauria. Efficacy of triphala churn ingredients against $A$. niger and potential of clove extract as herbal fungi toxicant. Biol Med 2010;2:1-9.

27. Kaushik S, Singh P. Antibacterial activity of different extracts of nutmeg (Myristica fragrans) against gram negative and gram positive pathogens. Vegetos 2012;25:282-6.

28. Thomas AR, Krishnakumari S. Phytochemical profiling of Myristica fragrans seed extract with different organic solvents. Asian J Pharm Clin Res 2015;8:303-7.

29. Dhale DA, Mogle UP. Phytochemical screening and antibacterial activity of Phyllanthus emblica (L.). Sci Res Repot 2011;1:138-42.

30. Devi PN, Kaleeswari S, Poonkothai M. Antimicrobial activity and phytochemical analysis of fruit extracts of Terminalia bellerica. Int J Pharm Pharm Sci 2014;6:639-42.

31. Abraham A, Mathew L, Samuel S. Pharmacognostic studies of the fruits of Terminalia bellirica (Gaertn.) Roxb. J Pharmacogn Phytochem 2015;3:45-52.

32. Nahor U, Ahmed Z. Antimicrobial activity of Phyllanthus emblica and Allium Sativum: comparative analysis of antimicrobial action of crude and ethanolic extract of these natural plant products. IOSR J Pharm Biol Sci 2012;4:21-6.

33. Ibrahim KM, Naem RK, Abd-Sahib AS. Antibacterial activity of nutmeg (Myristica fragrans) seed extracts against some pathogenic bacteria. J Al-Nahrain Uni Sci 2013;16:188-92.

34. Elizabeth KM. Anti-microbial activity of Terminalia bellerica Indian J Clin Biochem 2005;20:150-3

35. Alam B, Zahan R, Hasan M. Antioxidant, antimicrobial and toxicity studies of the different fractions of fruits of Terminalia bellerica Roxb. Global J Pharmacol 2011;5:7-17.

36. Badoni H, Sharma P, Waheed SM, Singh S. Phytochemical analyses and evaluation of antioxidant, antibacterial and toxic properties of Emblica officinalis and Terminalia bellirica fruit extracts. Asian J Pharm Clin Res 2016;6:96-102.

\section{How to cite this article}

- Sushma KS, Puttaswamy Rajeshwari, Koteshwar Anandrao Raveesha. Comparative study of mycoflora, antibacterial activity and phytochemistry of selected fresh and stored medicinal fruits. Int J Pharm Pharm Sci 2017;9(10):43-48. 